\title{
A first-in-man, double blind, placebo controlled study of the candidate therapeutic vaccine Opal-HIV-Gag(c) in HIV infected patients receiving HAART
}

AG Jackson*, HN Kløverpris, A Handley, P Hayes, J Gilmour, M Atkins, B Walker, J Ackland, M Sullivan, P Goulder

From AIDS Vaccine 2012

Boston, MA, USA. 9-12 September 2012

\section{Background}

Preclinical studies of overlapping 15 mer peptides spanning SIV, SHIV or HIV pulsed autologously ex vivo have demonstrated high level, virus-specific $\mathrm{T}$ cells responses and viral load suppression in Macaca nemestrina. The objective of this study was to evaluate the safety and preliminary immunogenicity of Clade $\mathrm{C}$ consensus peptides administered ex vivo to HIV positive adults.

\section{Methods}

Synthetic 15 mer peptides ( $\mathrm{n}=123$, Opal-HIV-Gag(c)) spanning Clade $C$, consensus Gag were manufactured to current good manufacturing practice and evaluated in a good laboratory practice toxicology study in Macaca mulatta. A first-in-human, single centre, placebo-controlled, doubleblind, dose escalation study was conducted. Twenty three people with well controlled HIV (CD4+ > 350cells/mm3 and a HIV $<400$ copies $/ \mathrm{mL}$ ), stratified by clade, were enrolled in four groups: $12 \mathrm{mg}(\mathrm{n}=6), 24 \mathrm{mg}(\mathrm{n}=7), 48 \mathrm{mg}$ $(\mathrm{n}=2)$ or matching placebo $(\mathrm{n}=8)$. Treatment was administered intravenously bedside (closed system) by enrichment of $120 \mathrm{~mL}$ of whole blood for WBCs using a Sepax S-100 device, ex vivo mixing the peptides (or diluent alone) and incubation at $37^{\circ} \mathrm{C}$ for one hour prior to reinfusion. Subjects received 4 administrations at 4 weekly intervals followed by a 12 week post-treatment follow up. Immunogencity was assessed by ELIspot.

\section{Results}

Opal-HIV-Gag(c) was generally well tolerated at doses of 12 and $24 \mathrm{mg}$. There was an increased incidence of temporally associated pyrexia, chills, rigor, and transient/self-limiting lymphopenia in Opal-HIV-Gag(c) recipients compared to placebo. Only 2 subjects were recruited to the $48 \mathrm{mg}$ cohort. A serious adverse event of anuria, hypotension and tachycardia secondary to diarrhoea occurred following a single dose of vaccine at $48 \mathrm{mg}$. No difference in ex vivo IFN- $\gamma$ ELISpot response was observed at any time.

\section{Conclusion}

An infectious cause for the event could not be identified, leaving the possibility of immunologically-mediated reaction to the vaccine thus leading to early termination of the study.

Published: 13 September 2012

doi:10.1186/1742-4690-9-S2-O54

Cite this article as: Jackson et al.: A first-in-man, double blind, placebo controlled study of the candidate therapeutic vaccine Opal-HIV-Gag(c) in HIV infected patients receiving HAART. Retrovirology 2012 9(Suppl 2): O54.

St. Stephen's AIDS Trust, London, UK

(c) 2012 Jackson et al; licensee BioMed Central Ltd. This is an Open Access article distributed under the terms of the Creative Commons :-1Wed Central Attribution License (http://creativecommons.org/licenses/by/2.0), which permits unrestricted use, distribution, and reproduction in any medium, provided the original work is properly cited. 